\title{
Malignant schwannoma of the obturator nerve
}

\author{
Kanta $\mathrm{M}^{1}$, Petera $\mathrm{J}^{2}$, Ehler $\mathrm{E}^{3}$, Prochazka $\mathrm{E}^{4}$, Lastovicka $\mathrm{D}^{1}$, Habalova $\mathrm{J}^{1}$, Valis $\mathrm{M}^{5}$, Rehak $\mathrm{S}^{1}$ \\ Department of Neurosurgery, Medical Faculty Charles University, Hradec Kralove, University Hospital \\ in Hradec Kralove, Czech Republic. kantam@lfhk.cuni.cz
}

\begin{abstract}
Lesions of obturator nerve are rare. Tumours and mainly malignant schwannoma of this nerve are extremely rare. The authors describe an unusual case of a gigantic schwannoma of the obturator nerve in 69 year old woman. Due to tumour expansion in the proximal part of the thigh MRI was performed and demonstrated extensive tumour originating most probably from the obturator nerve. The patient had no neurological symptoms. Biopsy from the lesion was taken at the Department of Orthopaedics with the following conclusion: malignant schwannoma. The patient received neoadjuvant chemotherapy due to diffuse metastatic spread on the chest $X$ ray, after which metastatic spread subsided. The main lesion reduced its size by $1 \mathrm{~cm}$. In $4 \mathrm{months}$ after biopsy the patient was referred for operation to neurosurgery. The tumour was removed along its borders and except of minimal weakness of adduction of the right thigh there was no neurological deterioration. She was subsequently referred for further care to oncology and radiotherapy.

The goal of this work is to emphasize the extremely rare occurrence of tumours of this nerve and suggest therapeutic options (Fig. 4, Ref. 11). Full Text in PDF www.elis.sk. Key words: obturator nerve lesion, malignant schwannoma, MPNST.
\end{abstract}

Abbreviations: CT - computed tomography, MRI - magnetic resonance imaging, MPNST - malignant peripheral nerve sheath tumor, US - ultrasonography

Obturator nerve lesions are rare. Tumours of this nerve were rarely reported $(1,2,3,4)$. These included metastases as well as primary tumours of the peripheral nerves (5). The nerve is surgically difficult to approach. With the availability of modern imaging methods, mainly MRI, CT and US, it is also possible to diagnose the tumours in this localisation (6).

The goal of our work is - based on the case report of our patient with large malignant schwannoma in obturator nerve - to demonstrate clinical characteristics, diagnostic options and successful neurosurgical therapy of this large and extremely rare tumour.

\section{Case report}

Our patient is 69 years old. She has been vivid active woman with a history of hypertension for 8 years. In August 2009 she

${ }^{1}$ Department of Neurosurgery, Medical Faculty Charles University, Hradec Kralove, University Hospital in Hradec Kralove, ${ }^{2}$ Department of Oncology and Radiotherapy, Medical Faculty Charles University, Hradec KraloveUniversity Hospital in Hradec Kralove, ${ }^{3}$ Department of Neurology Regional Hospital in Pardubice, Faculty of Health-Care University of Pardubice, ${ }^{4}$ Department of Orthopaedics, Medical Faculty Charles University, Hradec Kralove, University Hospital in Hradec Kralove, and ${ }^{5}$ Department of Neurology, Medical Faculty Charles University, Hradec Kralove, University Hospital in Hradec Kralove

Address for correspondence: M. Kanta, MD, PhD, Department of Neurosurgery, University Hospital, Sokolovska 581, CZ-500 05 Hradec Kralove, Czech Republic.

Phone: +420.777330975 , Fax: +420.495833024

Acknowledgement: Dedicated to research project UK PRVOUK P 37/04. started to observe a tumour growing on the medial aspect of her right thigh under the groin, which was gradually enlarging. Apart from a certain feeling of pressure under the inguinal ligament, she had no complaints and no neurological deficit. After a visit in orthopaedic clinic MRI was performed with a finding of an extensive - most probably malignant expansion originating most probably from the obturator nerve and passing down to the small pelvis with a size of 12x10x10 cm (Figs 1 and 2). Femoral vessels and femoral nerve were pushed laterally and to the front, sciatic nerve was separated with a layer of tissue, the tumour was infiltrating about $1.5 \mathrm{~cm}$ of vagina and $4 \mathrm{~cm}$ of rectum. Biopsy from the lesion was performed in the Department of Orthopaedics with the following conclusion: malignant schwannoma of peripheral nerve. Due to the finding on the chest X ray (diffuse metastatic spread) (Fig. 3) neoadjuvant chemotherapy was administered: (doxorubicin 75 $\mathrm{mg} / \mathrm{m}^{2}$ each 3 weeks, 7 cycles)

During the next follow ups there was a significant reduction in the number of metastases (Fig. 4) and the actual lesion was reduced by $1 \mathrm{~cm}$. US and CT examination of the abdomen has not shown any spread to the lymph nodes in the groin and small pelvis.

At this stage the patient was referred for surgical procedure to the Department of Neurosurgery. We managed to totally remove the relatively well circumscribed tumour originating from obturator nerve. There were no complications. The patient was referred for further care to an oncologist. Chemotherapy with Ifosfamid $5000 \mathrm{mg} / \mathrm{m}^{2} / 24$ hours followed in continual infusion with the support of G-CSF and uroprotection with an interval of 3 weeks (Mesna preparation). There were totally 3 cycles administered. After that followed another 3 cycles with a combination of ifosfamide with doxorubicin $50 \mathrm{mg} / \mathrm{m}^{2}$. Chemotherapy was completed on 25.11.2010. 

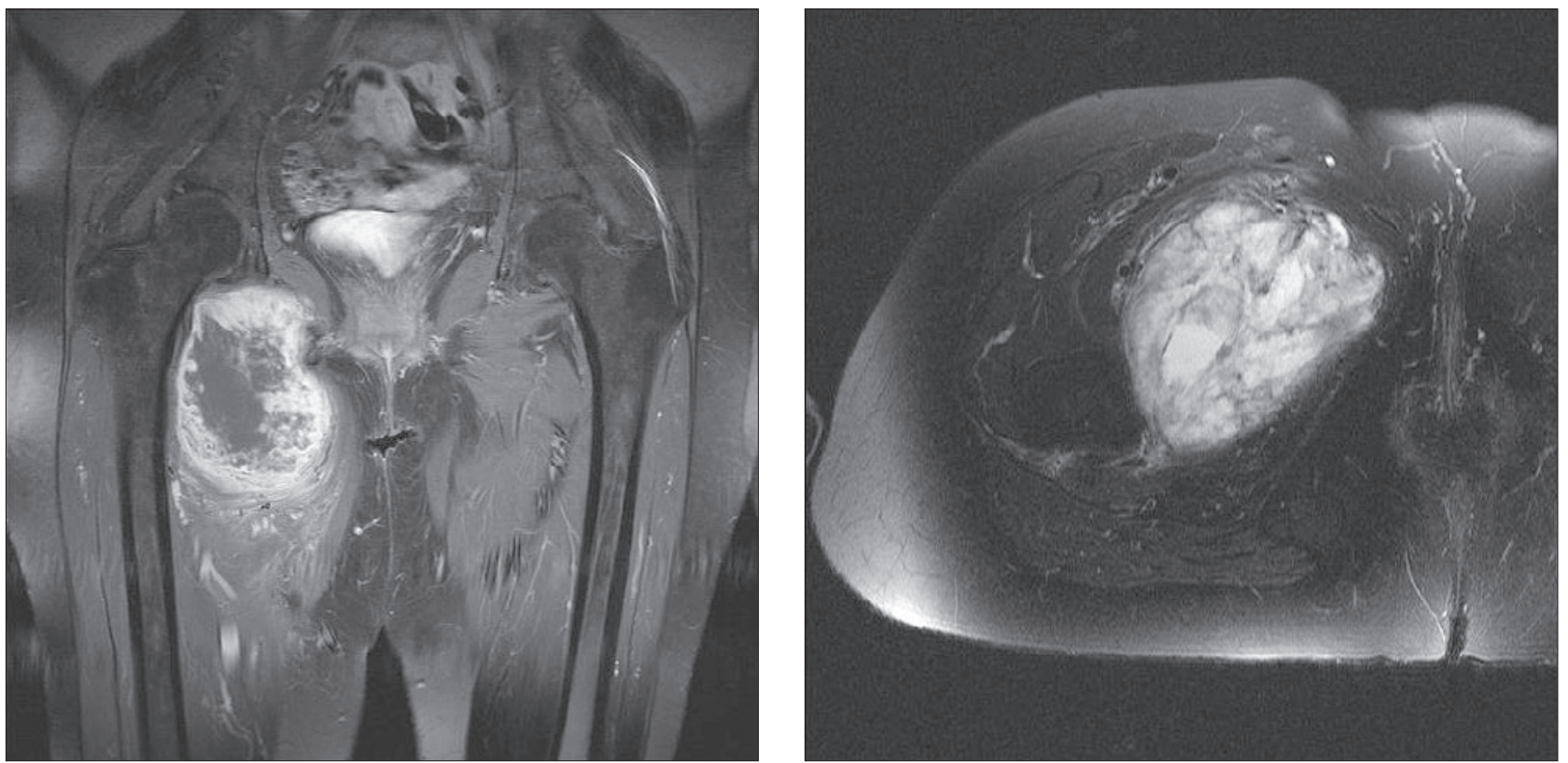

Figures 1 and 2. Obturator nerve tumor in coronar and transversal view on MRI.

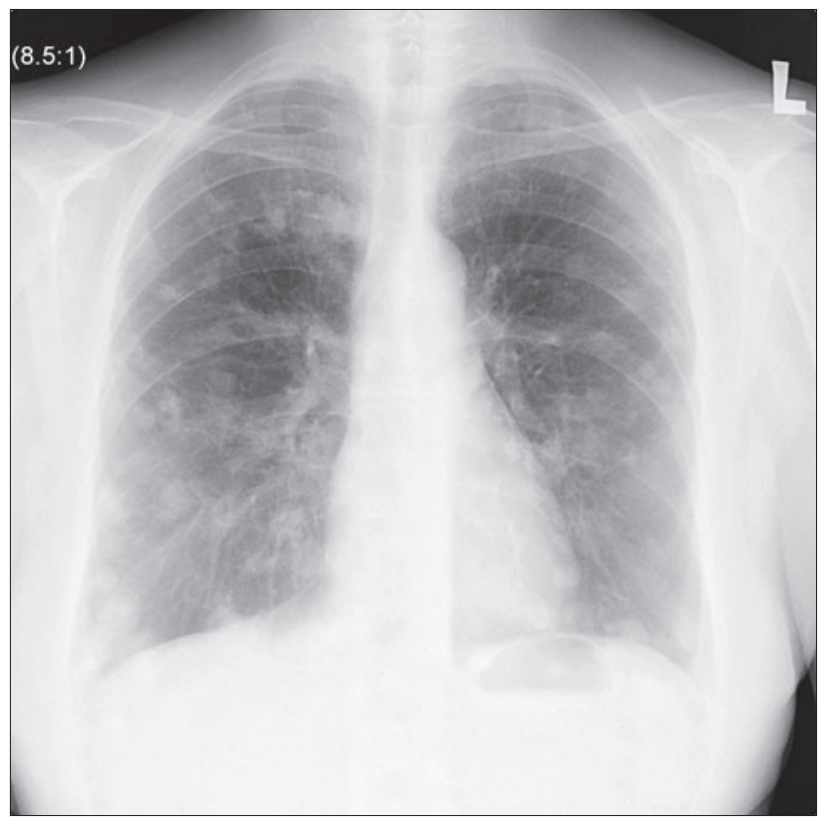

Fig. 3. Chest $X$ rays with diffuse metastatic spread.

CT examination from 2.1.2011 showed persisting lesions in the lungs up to $1 \mathrm{~cm}$, the finding is stable.

The patient has no complaints and no signs of local recurrence. Due to the previous treatment with doxorubicin is the patient regularly followed up in cardiology with a normal finding.

\section{Discussion}

Currently the malignant tumours of the peripheral nerves are called with a general name: malignant peripheral nerve sheath

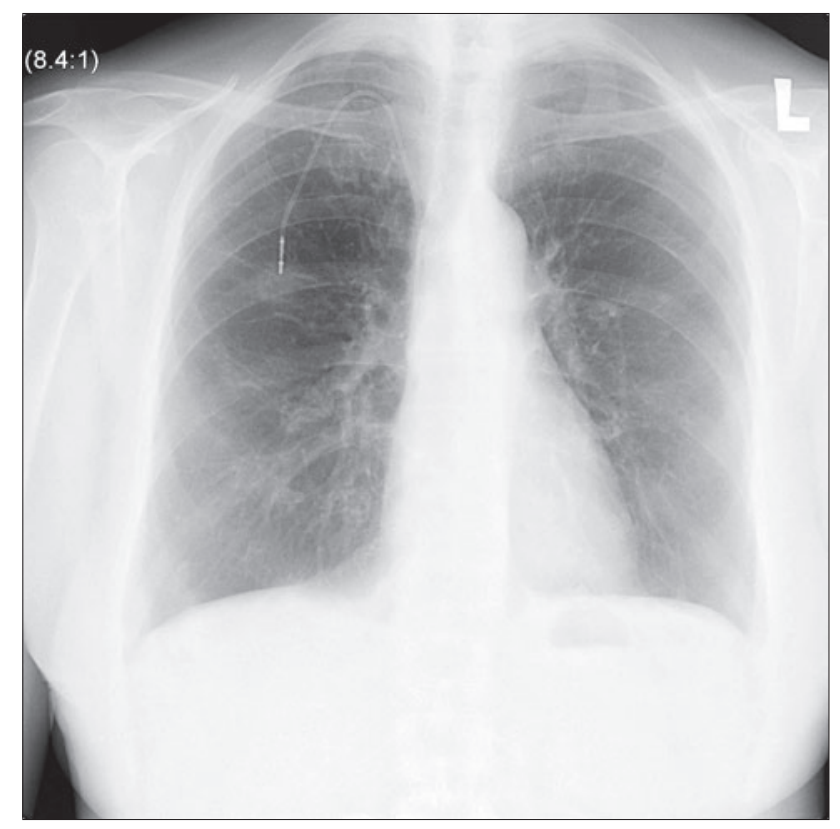

Fig. 4. Chest $X$ rays after neoadjuvant chemotherapy.

tumours (MPNST). MPNST are any clinically or histological malignant tumours originating from the cells in peripheral nerve sheaths. These tumours represent approx. $10 \%$ of all soft tissue sarcomas. They occur in 3 forms - sporadic, related with neurofibromatosis type 1 and as a consequence of irradiation. 2-16\% of patients with neurofibromatosis type 1 develop MPNST (5). On the other hand, up to a half of patients with MPNST has neurofibromatosis type I. Metastasizing MPNST occur in approx. $10 \%$ $(7,8)$. Prognosis of malignant tumours of the peripheral nerves is generally uncertain. Five years survival is reported as $43 \%$, sur- 
vival rate reported among various authors are variable. The reports of Cashen DV are different however, he reports up to $85 \%$ survival in $11 /+5$ years. Up to $40 \%$ of cases develop local recurrence; tumours have a tendency to metastasize to the lungs, bones, pleura and retroperitoneum and to the regional lymph nodes.

Other oncological therapy is also problematic, there are attempts for chemotherapy and radiotherapy reported $(7,9,10)$.

In our hospital we diagnosed multiple metastases in the lungs already at the time when the tumour was demonstrated in the groin during the hospitalization in the Department of Orthopaedics.

In most malignant PNST is the first therapeutic procedure early radical surgery of the tumour $(6,10)$. It is possible to proceed also with amputation of the limb. In patients with multiple metastases it is necessary to consider neoadjuvant therapy. This procedure is used only rarely. According to references, however, the success rate of this procedure - i.e. reduction to disappearance of metastases - is not high (10). Different is data on the effect of tumour irradiation (11). In our case, the oncology specialist decided to use neoadjuvant chemotherapy due to the metastatic spread. This was surprisingly significantly effective - metastases in the lungs were reduced and the matter of tumour in the groin slightly reduced (according to MRI) (Figs 1 and 2. Radical extirpation of the tumour was performed in this phase. The surgery was sufficiently radical (according to the follow up MRI) and the oncologist has not indicated any local irradiation.

\section{Conclusion}

The authors described a very rare case of extensive tumour of the right thigh. This was a malignant schwannoma originating from the obturator nerve. Due to metastases into the lungs neoadjuvant chemotherapy was administered, after which the number of metastases and the size of tumour reduced. After that followed total excision of a large tumour with residual lesion of obturator nerve. The patient survived 1.5 years since the first symptoms with a very good quality of life.

\section{References}

1. Aubert J, Debials F, Levillain P. Schwannoma of the obturator nerve with urologic manifestation. report of a case. Ann Urol (Paris) 2000; 34 (1): 58-65.

2. Park NY, Chong GO, Leee YS. Laparoscopic resection of schwannoma in the anomaly of obturator nerve. J Laparoendosc Adv Surt Tech A 2007; 17 (6): 769-773.

3. Scotto V, Rosica G, Valeri B, Limiti MR, Corti E. Bening schwannoma of the obturator nerve: a case report. Am J Obstet Gynecol 1998; 179: 816-817.

4. Tsukahara Y, Sato M, Kato J, Hirbayashi T, Fukuta T. Case report of malignant primary nerve sheath tumor arising in the female pelvis. Nippon Sanka Fujinka Gakkai Zasshi 1985; 37 (9): 1915-1918.

5. Stewart JD (Ed). Focal peripheral neuropathies. 3rd edition. Philadelphia: Lippincott Williams Wilkins, 2000, 580 pp.

6. Kitagawa R, Kim D, Reid N, Kline D. Surgical management of obturator nerve lesions. Neurosurgery 2009; 65 (Suppl 4): A24-A28.

7. Cashen DV, Parisien RC, Raskin K, Hornice FJ, Gebhardt MC, Mankin HJ. Survival data for patients with malignant schwannoma. Clin Orthop Relat Res 2004; 426: 69-73.

8. Shimizu K, Okita R, Uchida Y, Hihara J. Long survival after resection for lung metastasis of malignant peripheral sheath tumor in neurofibromatosis 1. Ann Thorac Cardiovasc Surg 2008; 14 (5): 322-324.

9. Kitamura M, Wada N, Nagata S, Iizuka N, Jin IF, Tomoeda M, Yuki M, Naka N, Araki N, Yutani C, Tomita Y. Malignant peripheral nerve sheath tumor associated with neurofibromatosis typ 1, with metastasis to the heart: a case report. Diagn Pathol 2010; 5: 2-6.

10. Porter DE, Prasad V, Foster L, Dall GF, Birch R, Grimer RJ. Survival in malignant peripheral nerve sheath tumors: a comparison between sporadic and neurofibromatosis type 1 - associated tumors. Sarcoma 2009; 2009: 756395 Epub 2009 Apr 7.

11. Stark AM, Buhl R, Hugo HH, Mehdorn HM. Malignant peripheral nerve sheath tumors - report of 8 cases and review of the literature. Acta Neurochir (Wien) 2001; 143 (4): 357-363.

Received December 5, 2011. Accepted July 20, 2013. 